\title{
Study of the niobium oxide structure and microscopic effect of plasma processing on the Nb surface
}

B. Giaccone ${ }^{1,2}$, M. Martinello1, J.F. Zasadzinski ${ }^{2}{ }^{1}$ FNAL, Batavia, IL 60510, USA - 2 IIT, Chicago, IL 60616, USA

\section{Abstract}

A study of the niobium oxide structure is presented here, focusing on the niobium suboxides. Multiple steps of argon sputtering and XPS measurements were carried out until the metal surface was exposed. Subsequently, the sample was exposed to air for different time intervals and the oxide regrowth was studied. In addition, three $\mathrm{Nb}$ samples prepared with different surface treatments were studied before and after being subjected to plasma processing. The scope is investigating the microscopic effect that the reactive oxygen contained in the glow discharge may have on the niobium surface. This study suggests that the $\mathrm{Nb}_{2} \mathrm{O}_{5}$ thickness may increase. Nevertheless, since the $\mathrm{Nb}_{2} \mathrm{O}_{5}$ is dielectric, its thickening would not negatively affect the cavity performance.

\section{Plasma processing to mitigate $\mathrm{FE}$}

- Reducing FE through $C_{x} H_{y}$ removal from cavity Nb surface

- Increasing the niobium work function by $10 \%$ results in $15 \%$ increase in $E_{\text {acc }}$

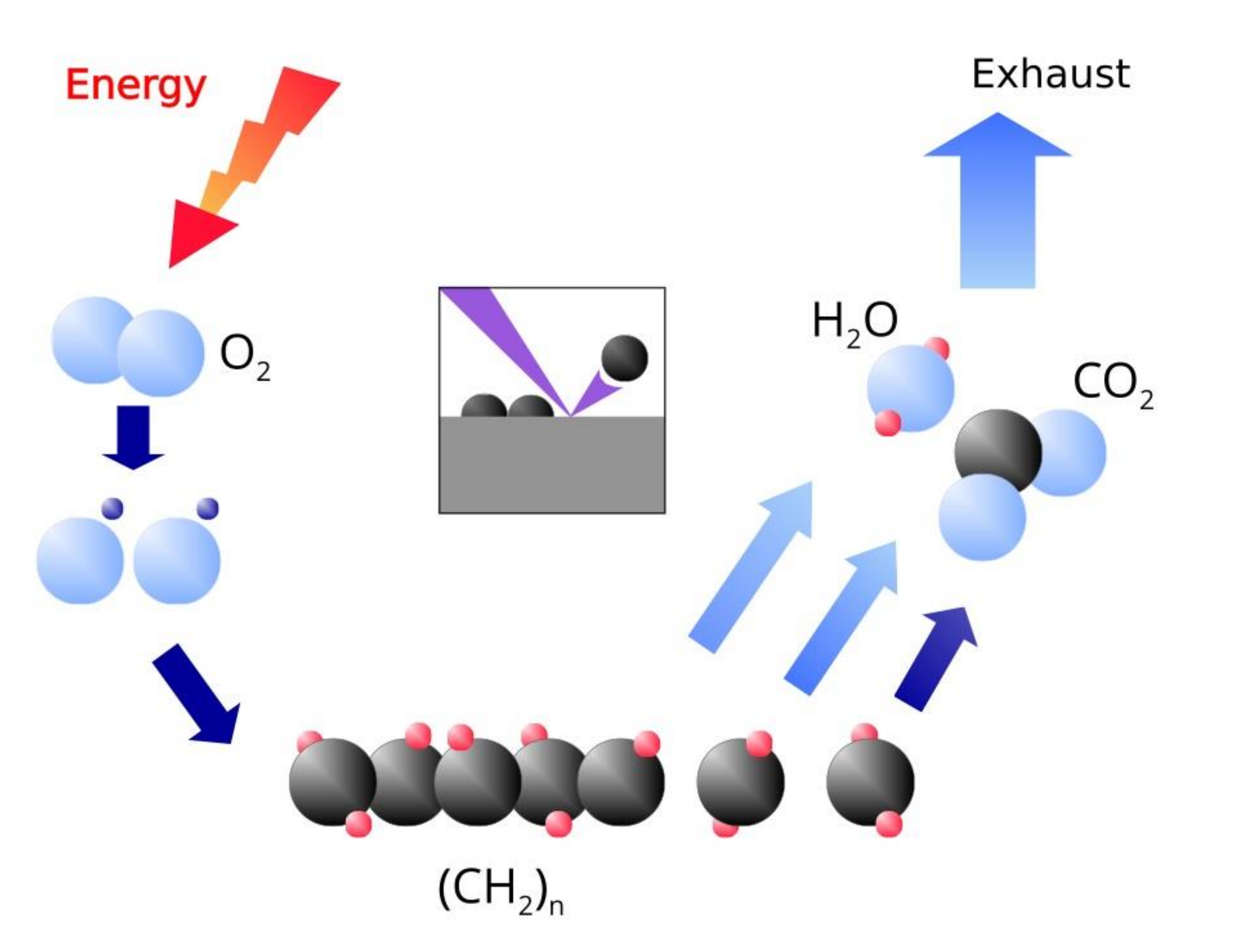

M. Doleans et al, NIMA 812 (2016)

P. Berrutti, B. Giaccone et al., J. Appl. Phys. 126, 023302 (2019) B. Giaccone et al., Phys. Rev. Accel. Beams 24, 022002

\section{Argon ions sputtering on oxidized $\mathrm{Nb}$ sample}

- Sample preparation: $800{ }^{\circ} \mathrm{C} \times 3 \mathrm{~h}+20 \mu \mathrm{m}$ $\mathrm{EP}+5 \mathrm{~min} \mathrm{HF}$ rinse

- After surface treatment: 1 week to fully oxidize prior to XPS measurement

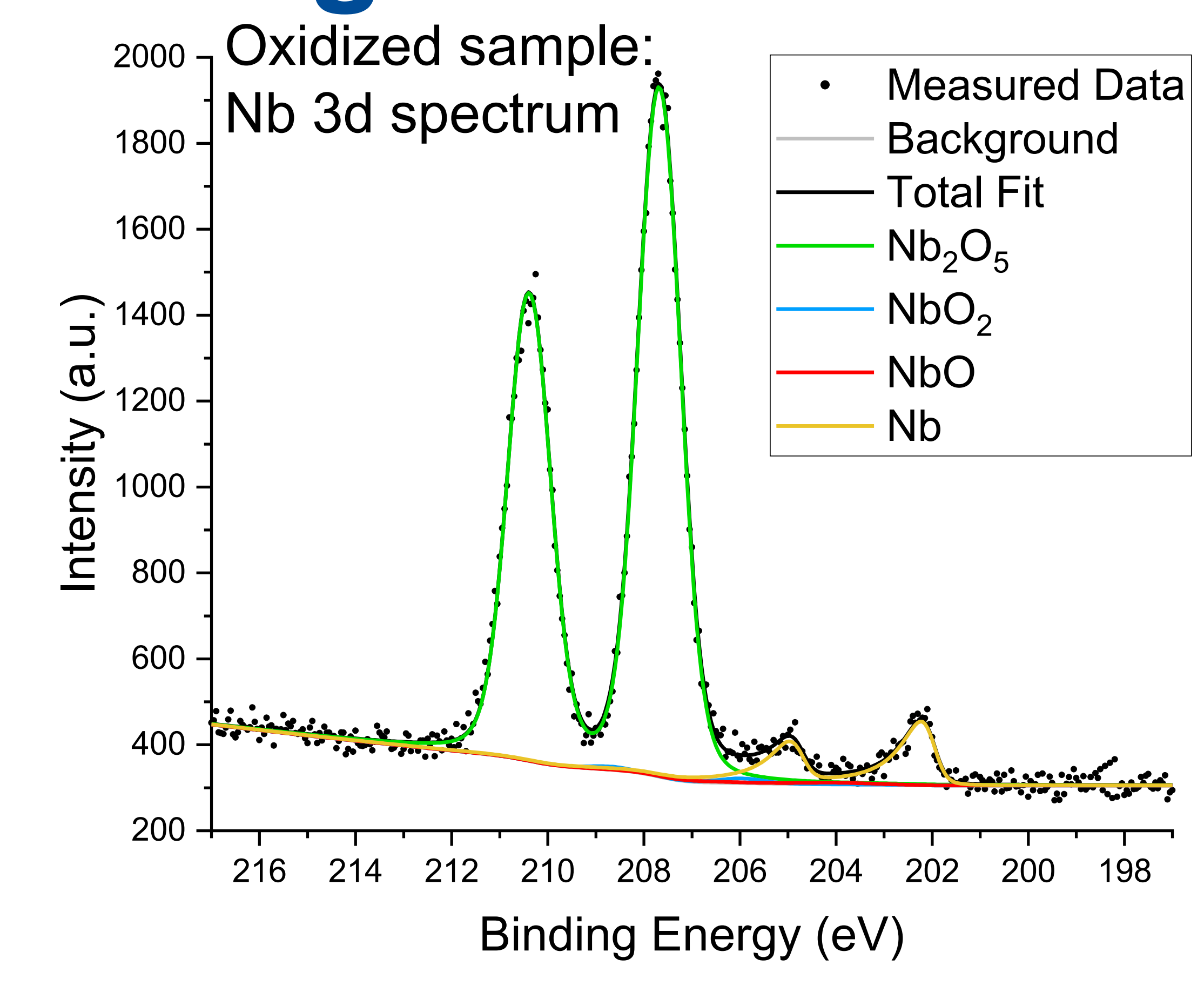

Spectra acquired during sputtering

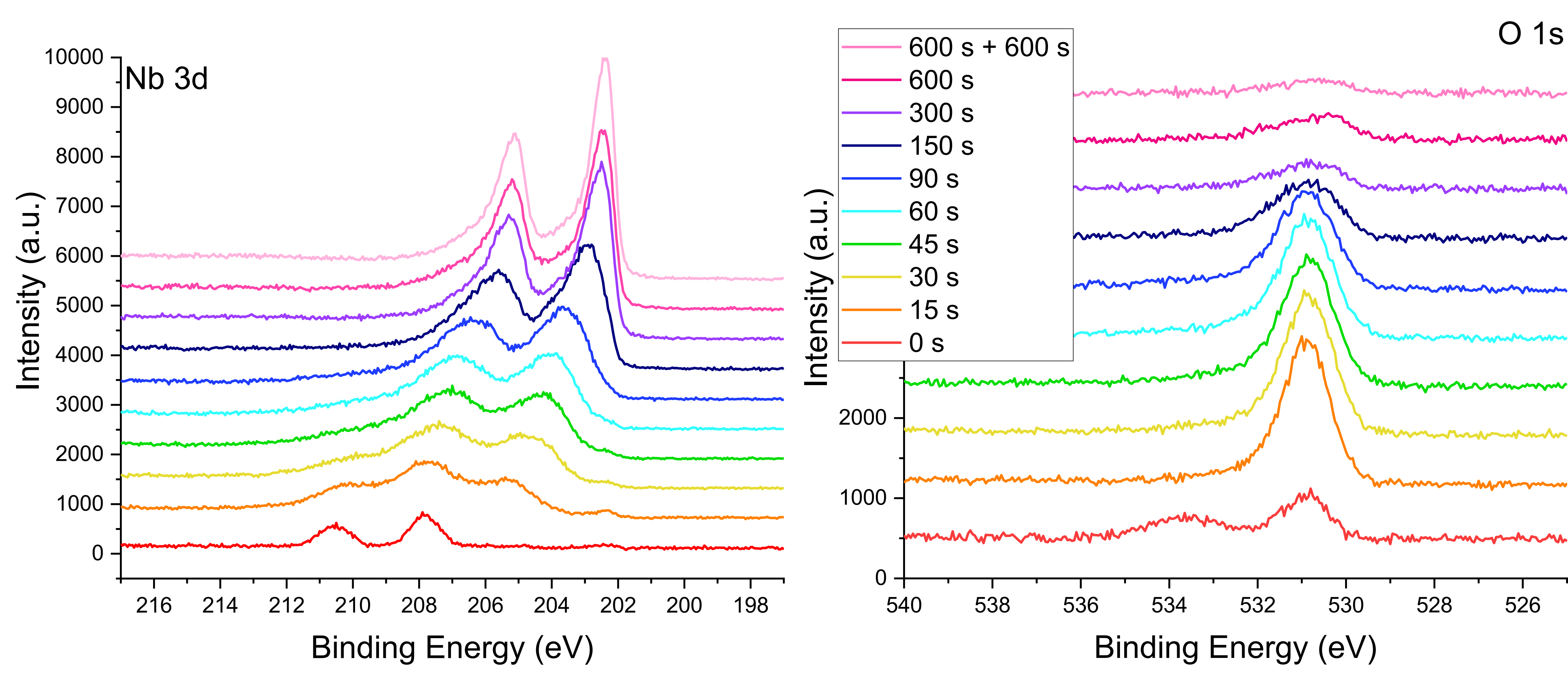

- $\mathrm{Nb} 3 \mathrm{~d}$ : shift towards lower energy values as the oxidation state decreases

- 0 1s: initially three peaks are detected: niobium oxide, $\mathrm{C}-\mathrm{O}, \mathrm{C}=\mathrm{O}$. The niobium oxide peak is due to $\mathrm{Nb}_{2} \mathrm{O}_{5}$ plus the suboxides O1s core level spectra

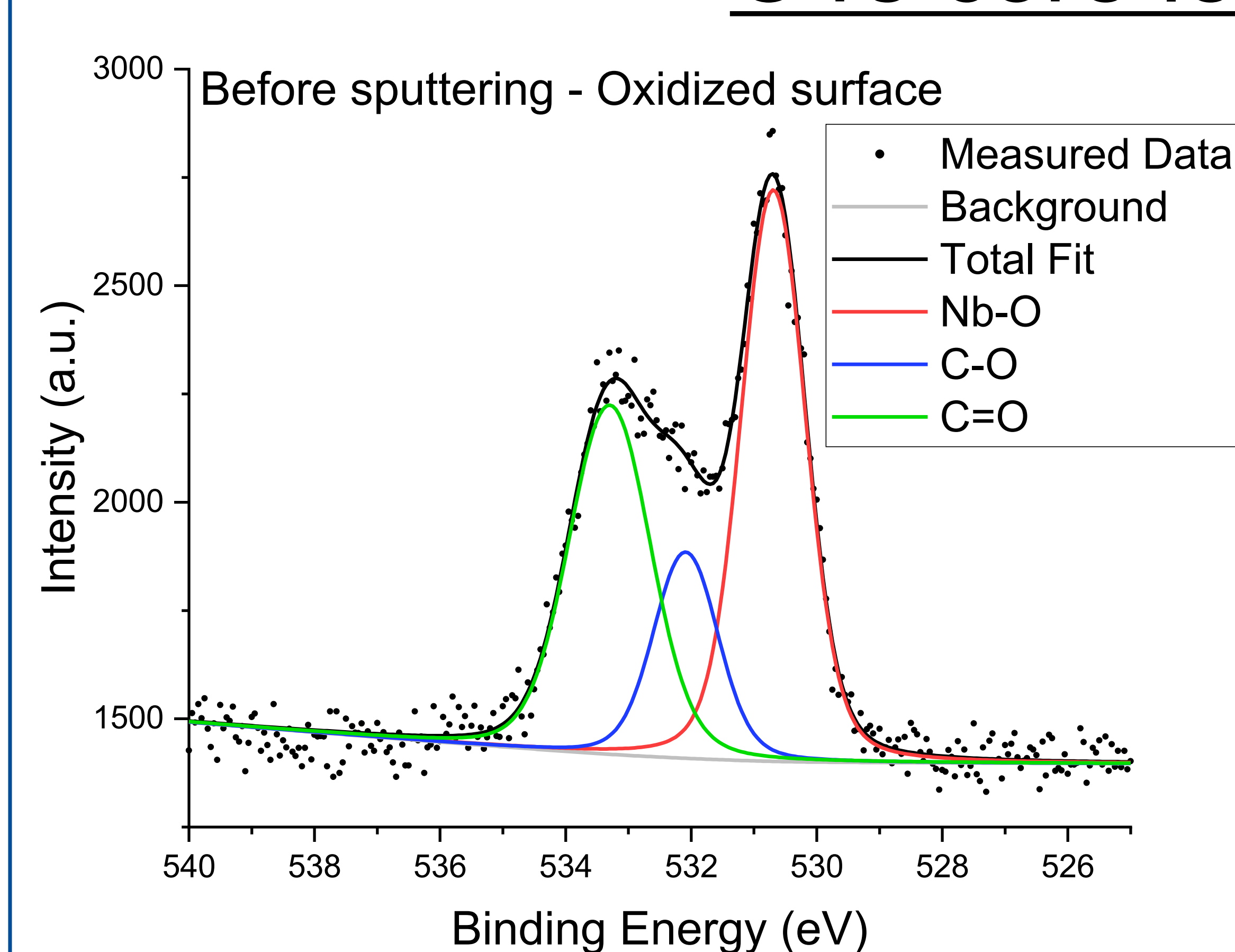

$\mathrm{Nb} 3 \mathrm{~d}$ core level spectra

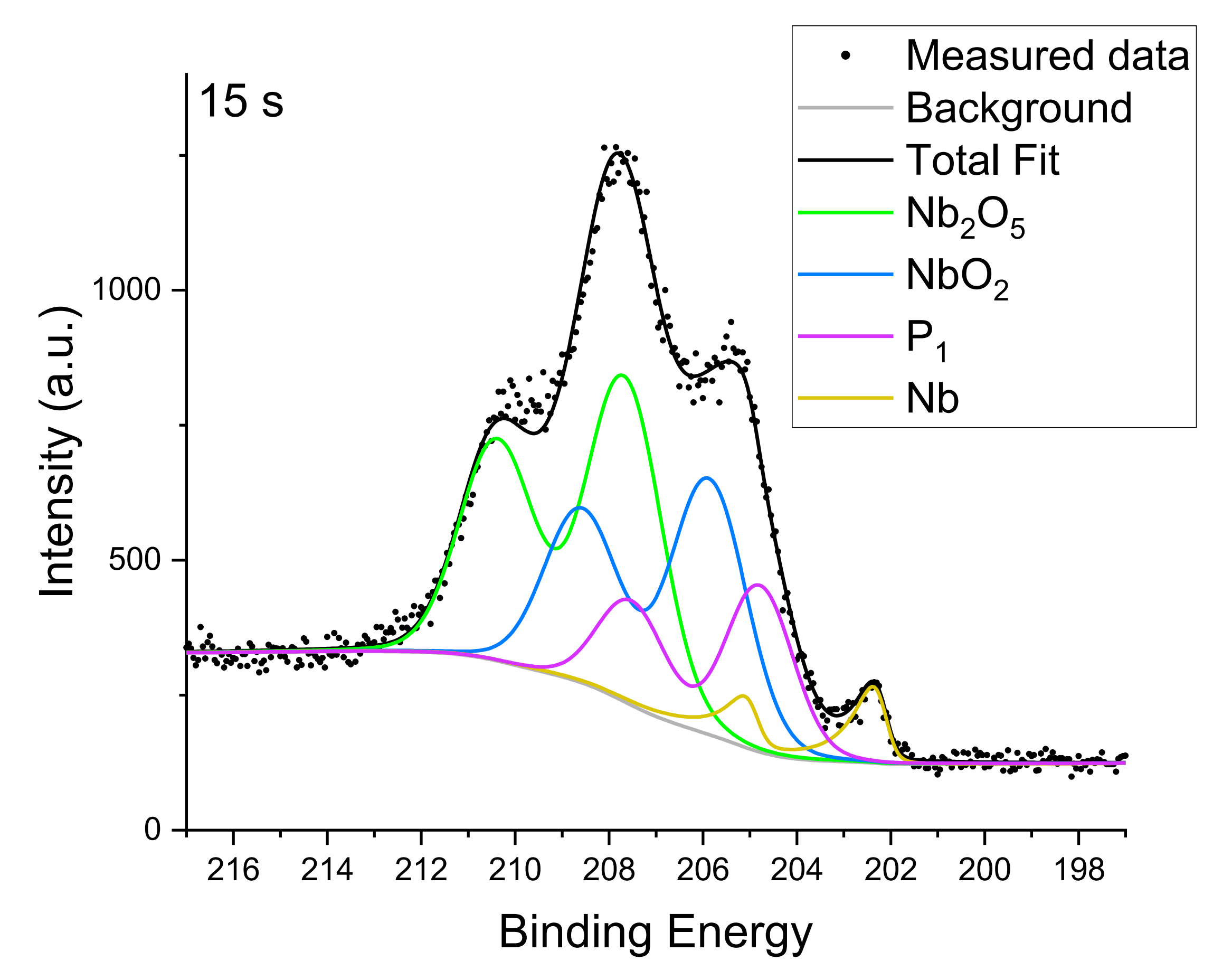

- Nb peak: $202.2 \mathrm{eV}$

- $\mathrm{P}_{1}: \mathrm{NbO}_{1+\mathrm{x}}$ peak: $204.8 \mathrm{eV}$

- $\mathrm{Nb}_{2} \mathrm{O}_{5}$ peak: $207.7 \mathrm{eV}$
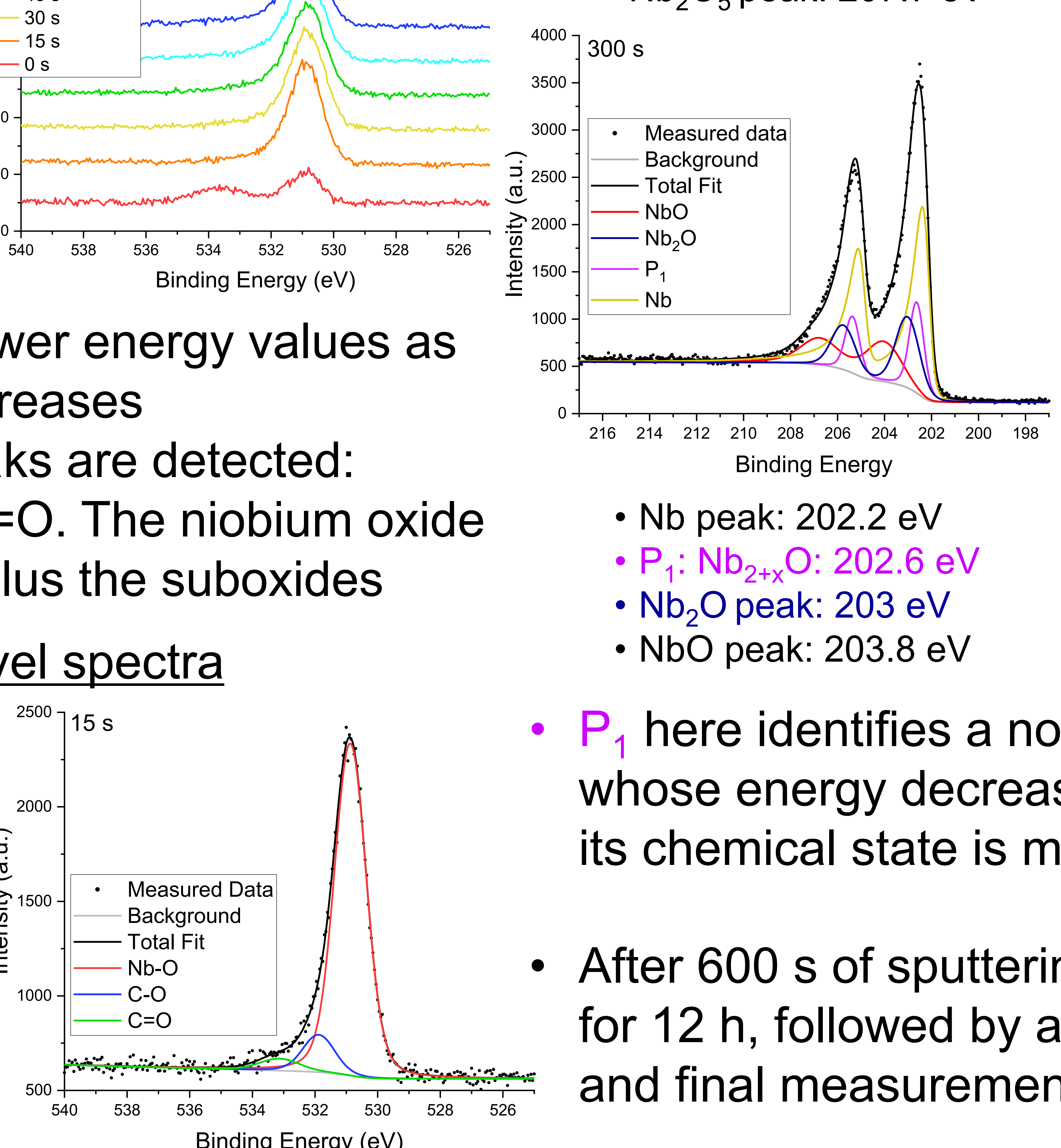

- $\mathrm{NbO}_{2}$ peak: $205.9 \mathrm{eV}$

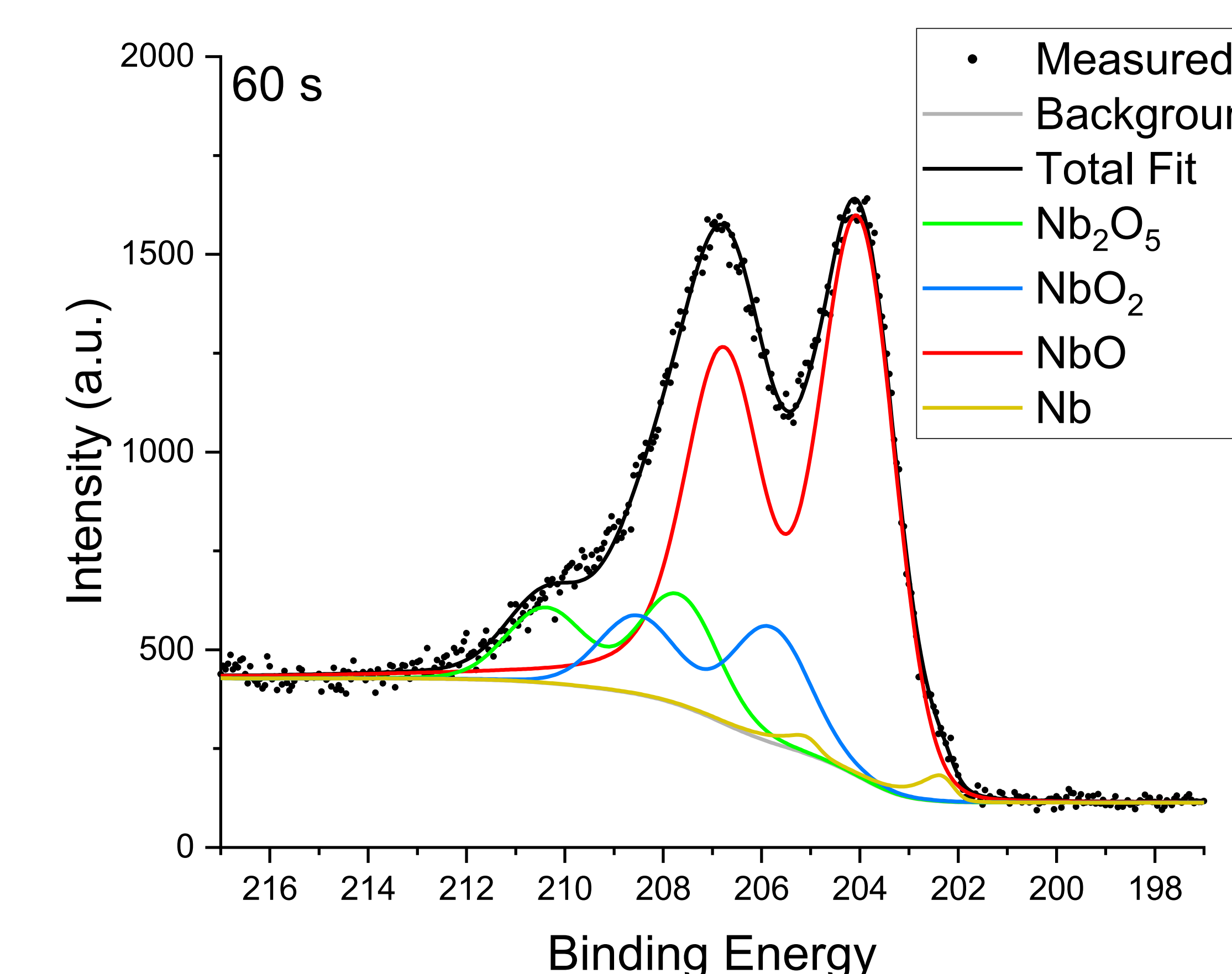

- Nb peak: $202.2 \mathrm{eV}$

- NbO peak: $203.8 \mathrm{eV}$

- $\mathrm{NbO}_{2}$ peak: $205.8 \mathrm{eV}$

- $\mathrm{Nb}_{2} \mathrm{O}_{5}$ peak: $207.8 \mathrm{eV}$

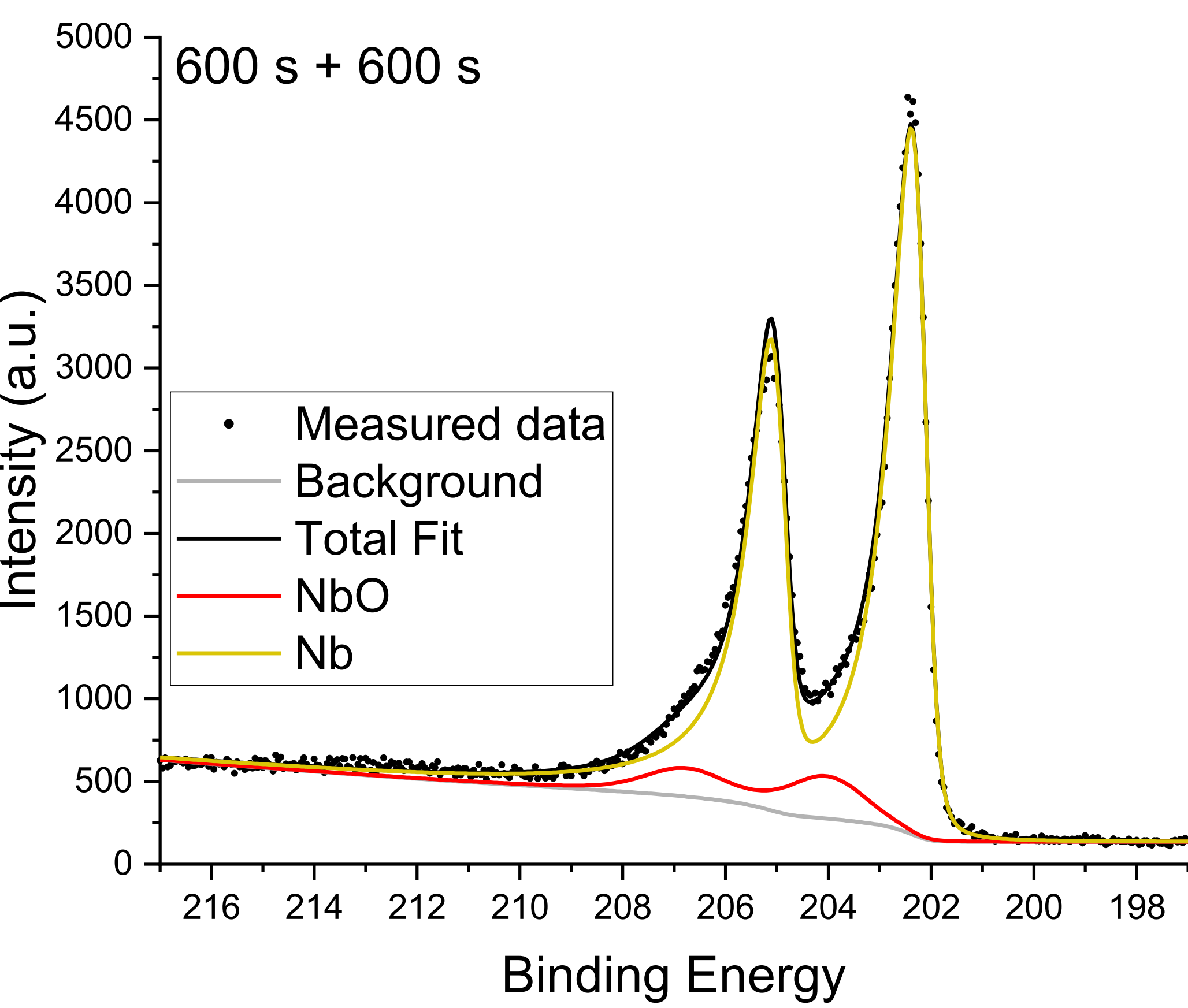

Nb peak: 202

- NbO peak: $203.8 \mathrm{eV}$

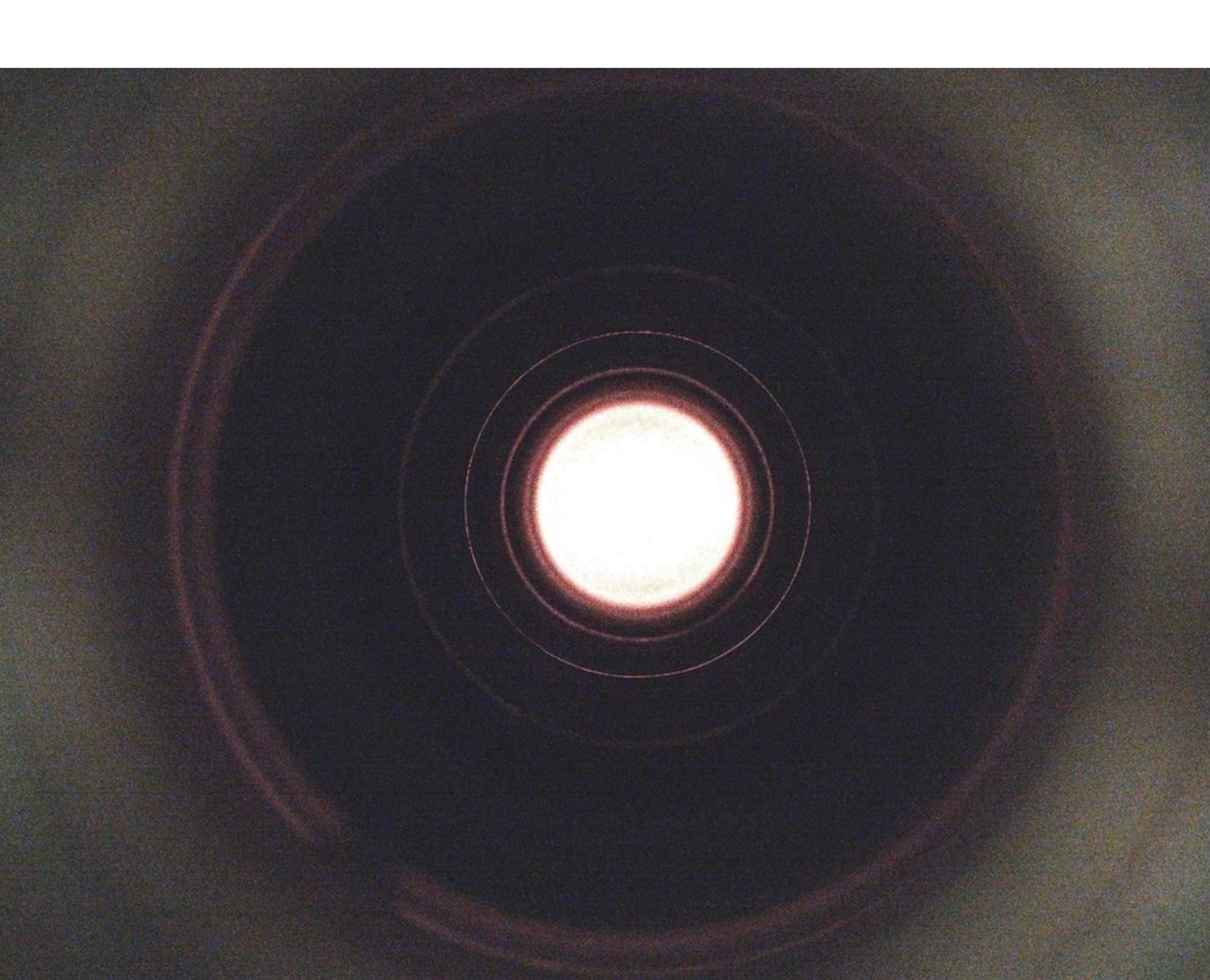

Fermilab whose energy decreases at each sputtering step as its chemical state is modified by the Ar ions.

After 600 s of sputtering: sample kept under vacuum for $12 \mathrm{~h}$, followed by additional $600 \mathrm{~s}$ of sputtering and final measurement prior to oxide regrowth in air. \section{.}




\section{Study of the niobium oxide structure and microscopic effect of plasma processing on the $\mathrm{Nb}$ surface}

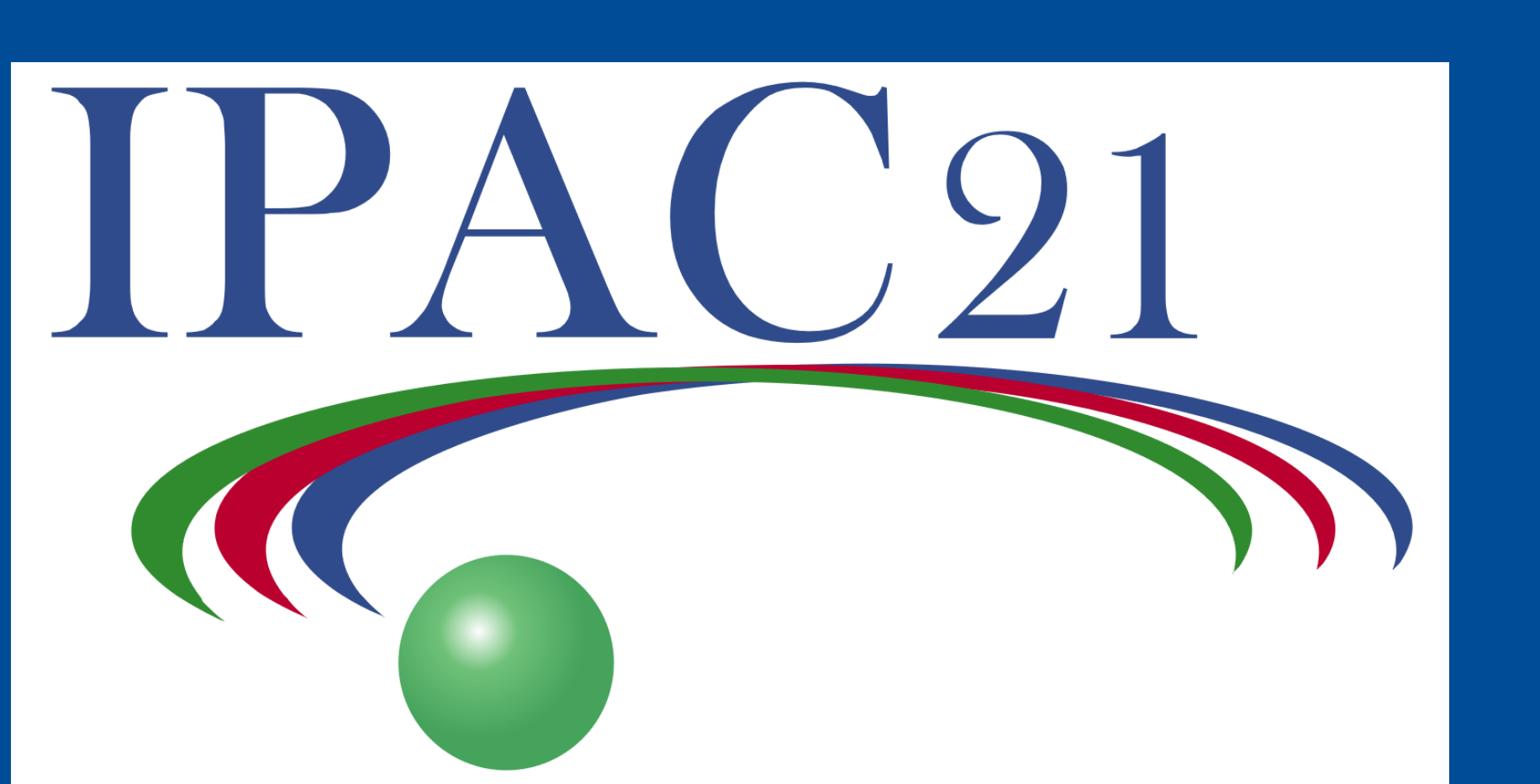

B. Giaccone ${ }^{1,2}$, M. Martinello1, J.F. Zasadzinski ${ }^{2}{ }_{1}$ FNAL, Batavia, IL 60510, USA - ${ }^{2}$ IIT, Chicago, IL 60616, USA

\section{Oxide growth through air exposure}

$\frac{\text { Air exposure steps }}{15 \text { min in air }+30 \text { min } \mathrm{AP}^{*}}$

Total of $(30 \mathrm{~min}$ in air +60 min $\mathrm{AP})+$ additional $38 \mathrm{~h}$ in vacuum

Additional $(45 \mathrm{~min}$ in air $+30 \mathrm{~min} \mathrm{AP})+38 \mathrm{~h}$ in vacuum

* 'AP': active pumping from atmosphere pressure to $10^{-9}$ Torr

After 75 minutes of exposure to air: surface has not reached full oxidization.

Multiple suboxides were identified through curve fitting: $\mathrm{NbO}, \mathrm{NbO}_{2}, \mathrm{Nb}_{2} \mathrm{O}$

The initial measurements taken on the oxidized sample showed possible traces of $\mathrm{NbO}$ and $\mathrm{NbO}_{2}$, but no $\mathrm{Nb}_{2} \mathrm{O}$ was detected.

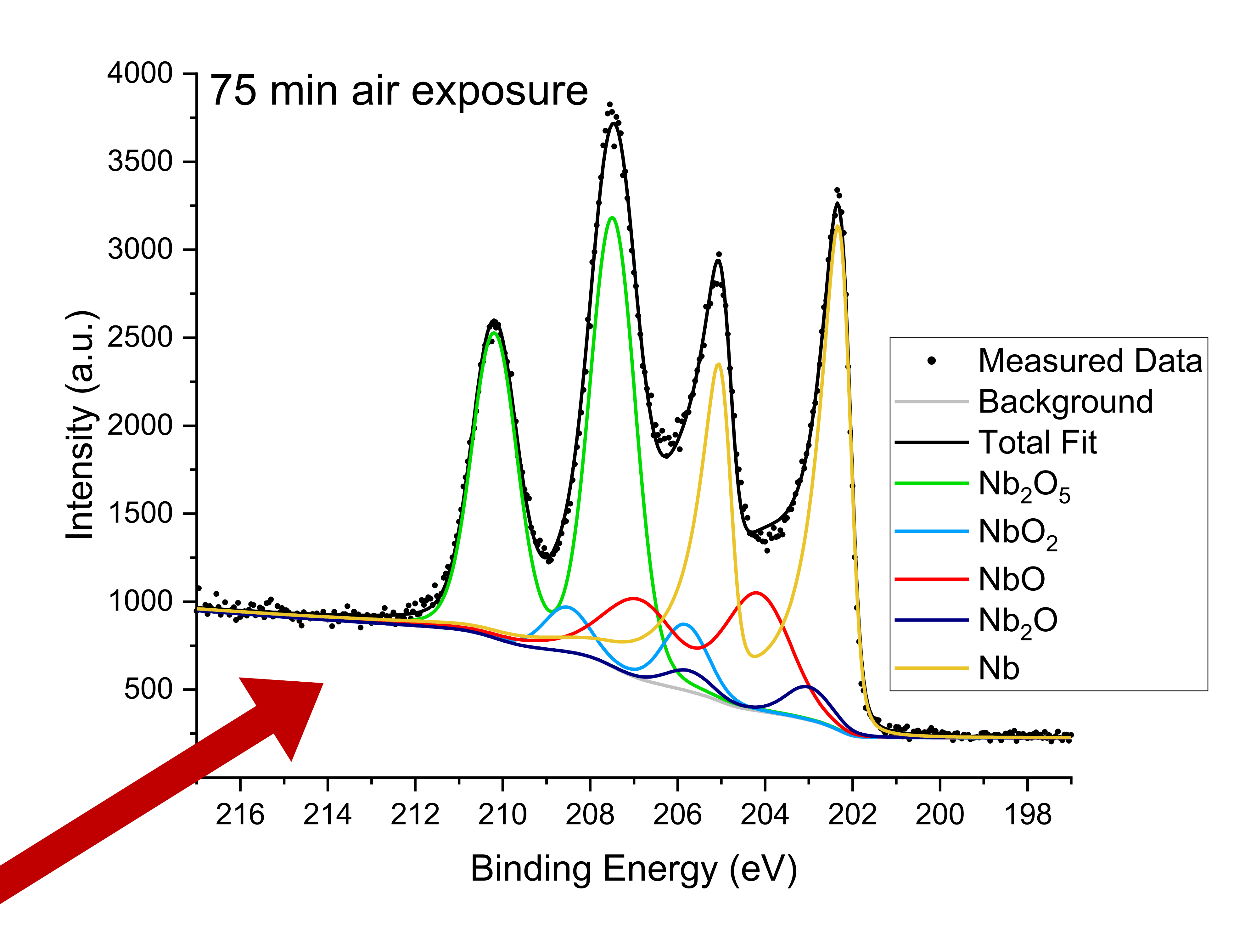

Ratio of the areas extracted through curve fitting \begin{tabular}{lllll}
\hline \hline Air exposure time & $\mathrm{Nb}_{2} \mathrm{O}_{5} / \mathrm{Nb}$ & $\mathrm{NbO}_{2} / \mathrm{Nb}$ & $\mathrm{NbO} / \mathrm{Nb}$ & $\mathrm{Nb}_{2} \mathrm{O} / \mathrm{Nb}$ \\
\hline $15 \mathrm{~min}$ & 0.87 & 0.12 & 0.36 & 0.08
\end{tabular} \begin{tabular}{lllll}
\hline $15 \mathrm{~min}$ & 0.87 & 0.12 & 0.36 & 0.08 \\
$30 \mathrm{~min}$ & 0.99 & 0.14 & 0.41 & 0.11
\end{tabular} $75 \mathrm{~min}$ $\begin{array}{llll}1.00 & 0.15 & 0.40 & 0.07\end{array}$

\section{XPS analysis on plasma processed $\mathrm{Nb}$ samples}

Sample preparation:

- $\mathrm{PH}$ 45: $800{ }^{\circ} \mathrm{C} \times 3 \mathrm{~h}+20 \mu \mathrm{m}$ EP

- $\mathrm{PH}$ 35: 2/6 N doping + $5 \mu \mathrm{m} \mathrm{EP}+5$ min HF rinse

- PH 40: 2/0 N doping + $7 \mu \mathrm{m}$ cold EP

Samples were positioned on cavity iris and plasma processed for $6 \mathrm{~h}$.

- Similar results obtained on all three samples, independently of the surface treatment

- No particular change was observed in the suboxide spectra

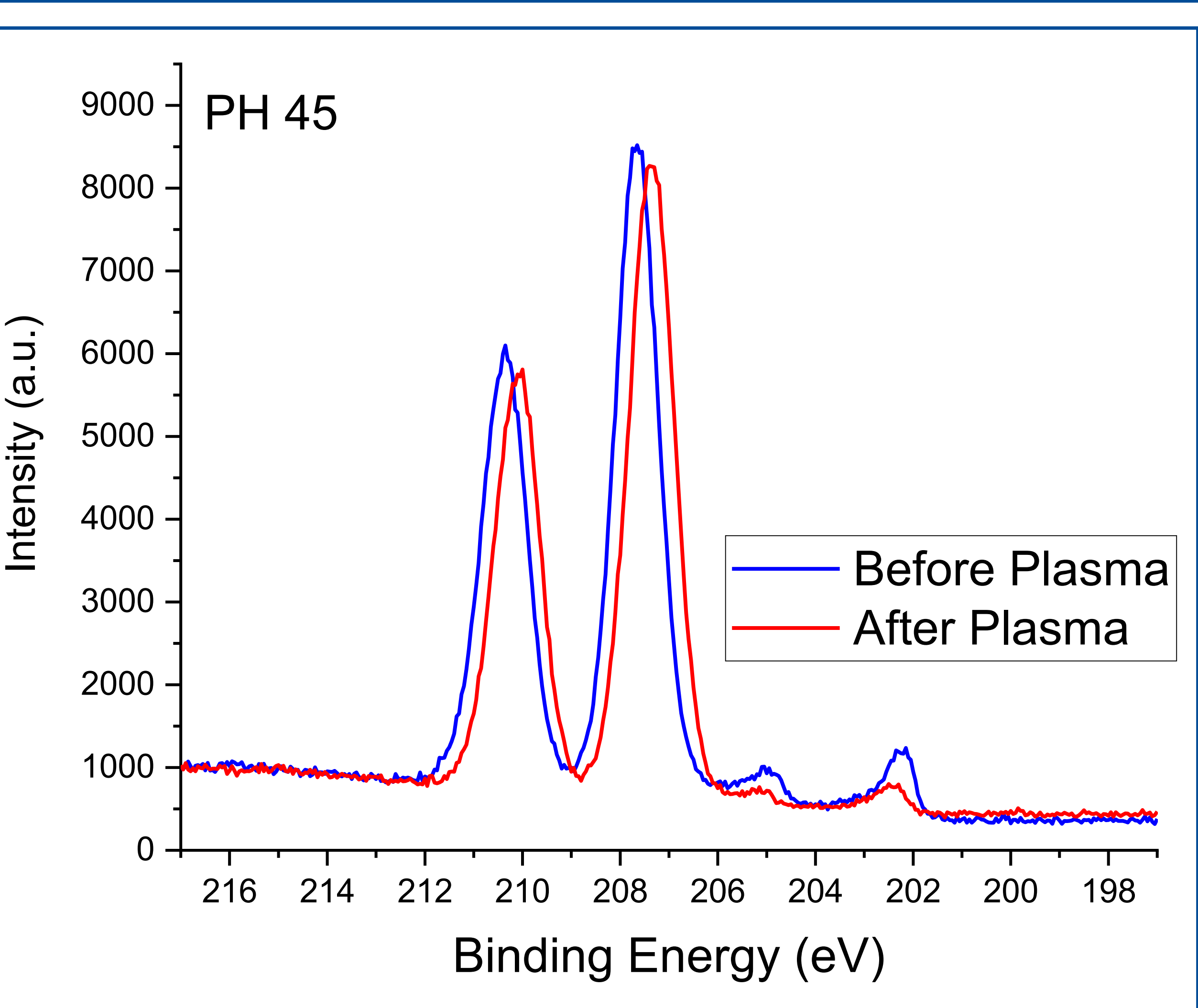

- $\Delta \mathrm{E}$ between $\mathrm{Nb}$ and $\mathrm{Nb}_{2} \mathrm{O}_{5}$ is decreased after plasma processing

- Relative intensity of $\mathrm{Nb}$ and $\mathrm{Nb}_{2} \mathrm{O}_{5}$ is modified: ratio of $\mathrm{Nb}_{2} \mathrm{O}_{5}$ area over $\mathrm{Nb}$ area consistently increases after plasma processing

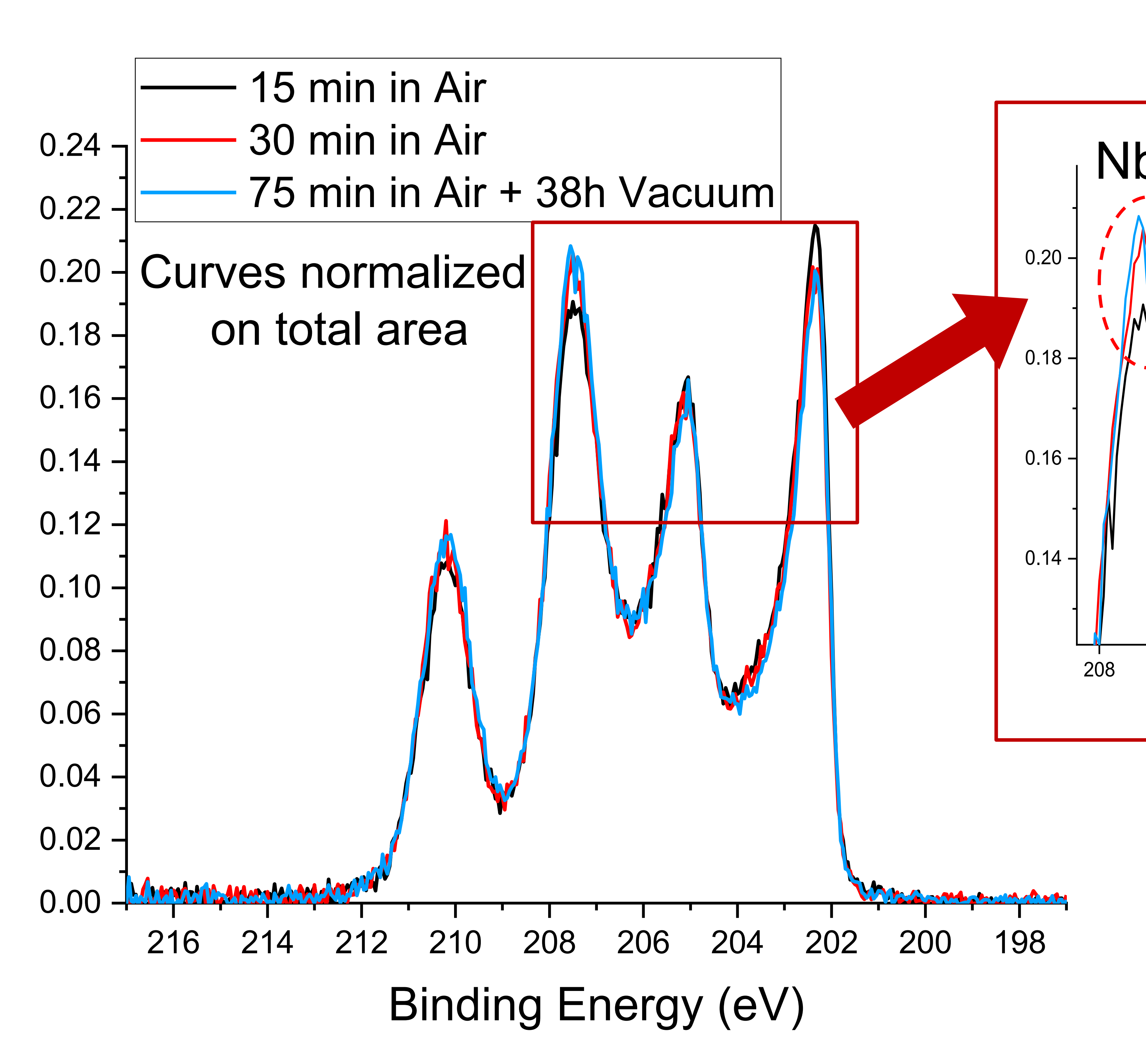

As the air exposure time increases:

increase of $\mathrm{Nb}_{2} \mathrm{O}_{5}$ peak, decrease of $\mathrm{Nb}$ metal peak. Ratio of suboxide area over metal $\mathrm{Nb}$ area remains constant.

\section{Conclusions}

- Sputtering and oxide regrowth: studied niobium oxide structure, identified multiple suboxides and extracted parameters for data analysis

- Plasma processed samples:

- Consistent change in $\mathrm{Nb}_{2} \mathrm{O}_{5} / \mathrm{Nb}$ area ratio suggesting oxide thickening

- Reduction in $\Delta \mathrm{E}$ between $\mathrm{Nb}_{2} \mathrm{O}_{5}$ and $\mathrm{Nb}$ peaks: reproducible but not fully understood yet. May be caused by oxygen vacancies in $\mathrm{Nb}_{2} \mathrm{O}_{5}$ lattice.

No major impact on cavity performance 